\title{
Two-Step Synthesis of Linear and Bent Dicarboxylic Acid Metalloligands with Lengths of up to Three Nanometers
}

\author{
Ophélie M. Planes, Suzanne M. Jansze, Rosario Scopelliti, Farzaneh Fadaei-Tirani and \\ Kay Severin*
}

Institut des Sciences et Ingénierie Chimiques, École Polytechnique Fédérale de Lausanne (EPFL), CH-1015 Lausanne, Switzerland Supporting Information Placeholder

\begin{abstract}
Nanometer-sized polycarboxylate ligands are interesting building blocks for metallasupramolecular chemistry, but access to these compounds is often limited by complicated synthetic pathways. Here, we describe a simple two-step protocol, which allows preparing linear and bent dicarboxylate ligands with lengths of up to three nanometers from commercially available compounds. The ligands are prepared by iron-templated polycondensation reactions involving arylboronic acids and nioxime. The final products contain two iron clathrochelate complexes, and two terminal carboxyphenylene groups. To demonstrate that the new ligands are suited for the construction of more complex molecular nanostructures, we have prepared a $\mathrm{Cu}$-based metal-organic polyhedron, which represents the largest $M_{4} L_{4}$ cage described so far.
\end{abstract}

\section{Introduction}

The molecular basis of metallasupramolecular chemistry are interactions of metal complexes with polydendate ligands. ${ }^{1}$ Two ligand classes have dominated the field: polypyridyl ligands, and ligands with two or more carboxylate groups. The latter are widely used for the synthesis of metal-organic frameworks (MOFs), ${ }^{2}$ but they have also been employed to prepare molecularly defined macrocycles 3 and cages (metalorganic polyhedra, MOPs). ${ }^{4}$ An advantage of polycarboxylates over polypyridyl ligands is the fact that carboxylate ligands can provide a charge compensation for the metal ions. Accordingly, it is possible to form charge-neutral assemblies and networks.

From a structural point of view, the key features of a polycarboxylate ligand are denticity (number of donor groups), geometry (orientation of the donor groups), flexibility, and size (distance between the donor groups). 'Size' matters, because it defines the spacing of the metal centers, and, accordingly, the potentially available void volume of MOFs, cages, and macrocycles. The synthesis of nanometersized polycarboxylates with sufficient solubility for solutionbased reactions is still a challenging task. In this context, we have explored the utilization of inert clathrochelate 5 complexes as scaffolds for the construction of polydentate metalloligands. ${ }^{6,7}$ We have focused on boronate ester-capped clathrochelates, because they are easily obtained in metal- templated condensation reactions. 5 Furthermore, the divergent side chains of these complexes prevent stacking interactions. As a consequence, the metalloligands tend to display good solubility in organic solvents.
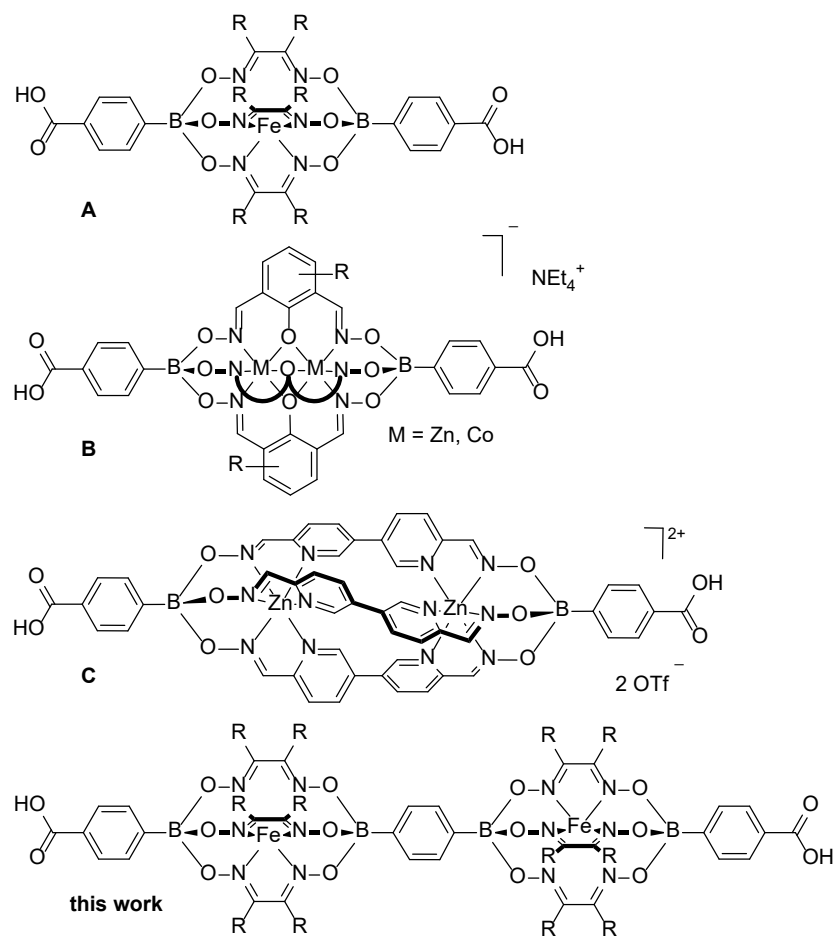

Figure 1 Examples of ditopic carboxylic acid ligands containing clathrochelate-type metal complexes.

Low spin Fe(II) complexes of type A (Figure 1) can be obtained by reaction of 4-carboxyphenylboronic acid with $\mathrm{FeCl}_{2}$ and a dioxime ligand.8,9 By using a phenol-based dioxime, it is possible to synthesize dinuclear $\mathrm{Zn}$ (II) and $\mathrm{Co}$ (II) complexes of type $\mathbf{B} .{ }^{8}$ Both, ligands $\mathbf{A}$ and $\mathbf{B}$, are robust enough to be used for the synthesis of MOFs. ${ }^{8}$ Recently, we have reported the synthesis ligand $\mathbf{C}$, which can be described as a capped helicate. ${ }^{10}$ The carboxylic acid groups in $\mathbf{C}$ are approximately $2.6 \mathrm{~nm}$ apart from each other $\left(\mathrm{O}_{2} \mathrm{C} \cdots \mathrm{C}^{\prime} \mathrm{O}_{2}\right.$ distance), which is substantially longer than what is found for metalloligands based on tetraphenylporphyrins $(\sim 1.9 \mathrm{~nm}) .^{11}$ However, the positive charge of $\mathbf{C}$ compromises its ability to 
form charge-neutral assemblies. Below, we describe the synthesis of dicarboxylic acid ligands containing two Fe(II) clathrochelate complexes. The new ligands have donor-donor distances of up to three nanometers, and they are suited for applications in metallasupramolecular chemistry, as evidenced by the synthesis of an $\mathrm{M}_{4} \mathrm{~L}_{4}$-type MOP.

\section{Results and Discussion}

Iron clathrochelate complexes can be obtained by reaction of boronic acids with $\mathrm{Fe}(\mathrm{II})$ salts and dioxime ligands (Scheme 1a). When the reaction is performed with a mixture of a diboronic acid and a monoboronic acid, it is possible to obtain an extended dinuclear complex in a single step (Scheme ib). We have previously used this approach to make large dipyridyl ligands. ${ }^{12,13}$ As expected, this multicomponent reaction is not selective, and mononuclear complexes are obtained along with higher oligomers. The formation of oligomers can be suppressed by using an excess of the monoboronic acid, but a chromatographic separation is in most cases needed to isolate the double clathrochelate complex in pure form. Size exclusion chromatography was found to be particularly useful for this purpose. ${ }^{12 a}$

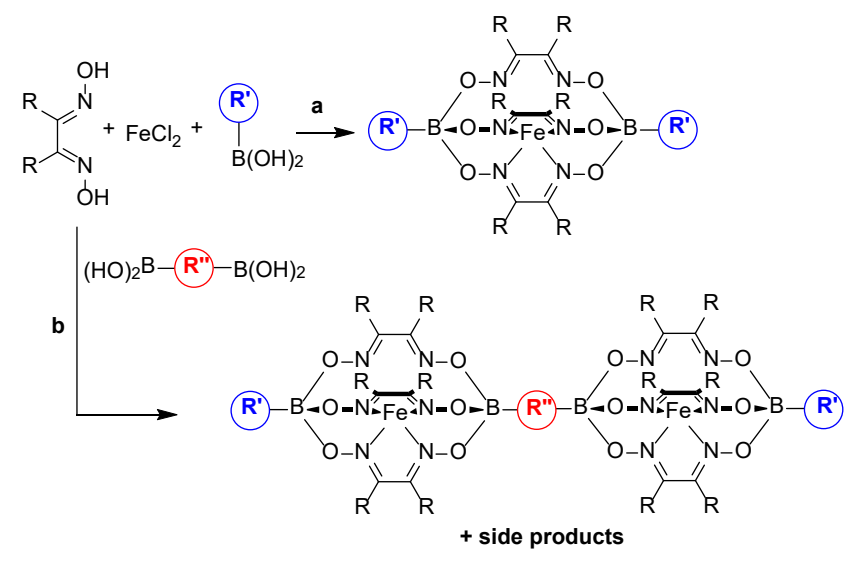

Scheme 1. Synthesis on Single- and Double Clathrochelate Complexes.

We wanted to use the procedure outlined in Scheme $1 \mathrm{~b}$ to make double clathrochelate complexes with terminal carboxylic acid groups. However, test reactions quickly revealed a problem: the products were only soluble in polar organic solvents, and a chromatographic separation of the product mixture was not accomplished. Therefore, we decided to use arylboronic acids featuring ester groups. Heating a mixture of nioxime (6 equiv), $\mathrm{FeCl}_{2}$ (2 equiv), 3- or 4ethoxycarbonylphenyl boronic acid (4 equiv, 2-fold excess), and 1,3- or 1,4-phenylenediboronioc acid (1 equiv) in methanol under reflux for $12 \mathrm{~h}$ gave a mixture of complexes. The desired dinuclear complexes 1-3 were isolated in yields between 14 and $27 \%$ (Scheme 2 ). The esters were characterized by ${ }^{1} \mathrm{H}$ and ${ }^{13} \mathrm{C}$ NMR spectroscopy, and by high resolution mass spectrometry. In addition, the solid state structures of 1-3 were determined by single crystal X-ray diffraction (Figure 2). For the linear complex $\mathbf{1}$, the terminal ester groups are $3 \mathrm{~nm}$ apart from each other $\left(\mathrm{O}_{2} \mathrm{C} \cdots \mathrm{C}^{\prime} \mathrm{O}_{2}\right.$ distance $)$. Due to the presence of a meta-connected phenylene spacer, the complexes 2 and 3 display an overall bent geometry, with the ester groups being $2.5 \mathrm{~nm}$ (2) and $2.1 \mathrm{~nm}$ (3) apart from each other. In line with what is observed for other Fe clathrochelate complexes, 5 the geometry around the Fe centers can be described as distorted trigonal prismatic.
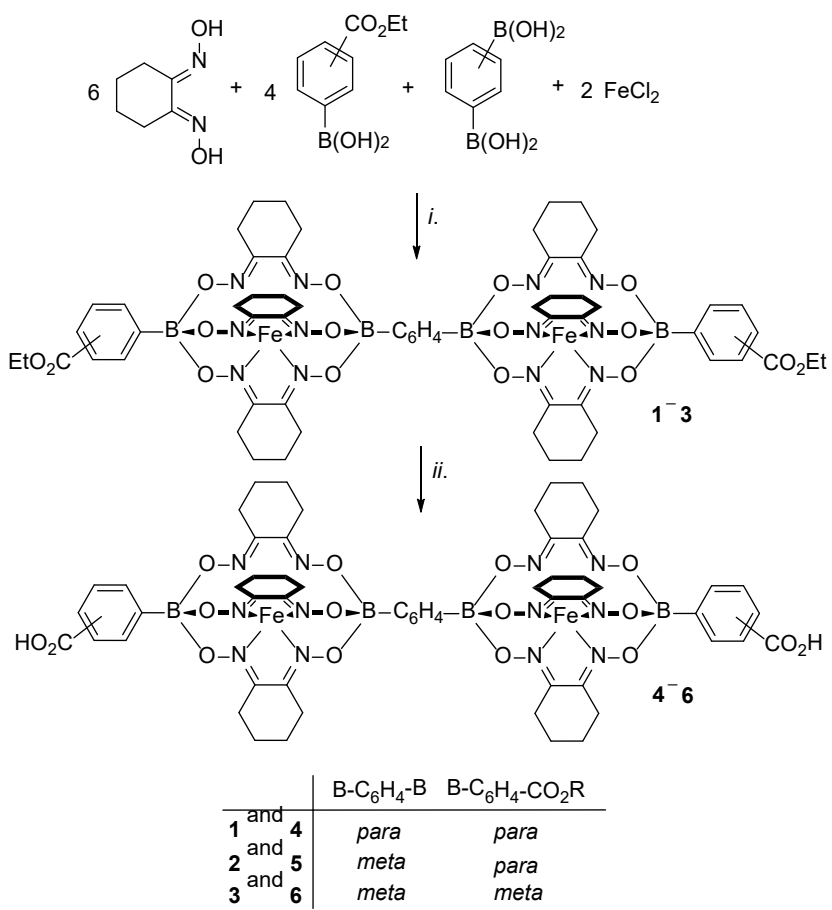

Scheme 2. Synthesis of the Double Clathrochelate Complexes 1-6. Conditions: (i) MeOH, Reflux, 12 h, 1427\% Yield; (ii) $\mathrm{H}_{2} \mathrm{O} / \mathrm{THF} / \mathrm{CH}_{2} \mathrm{Cl}_{2} / \mathrm{MeOH}, \mathrm{NaOH}$ (100 Equiv), $60^{\circ} \mathrm{C}, 2-12 \mathrm{~h}, 62-85 \%$ Yield.
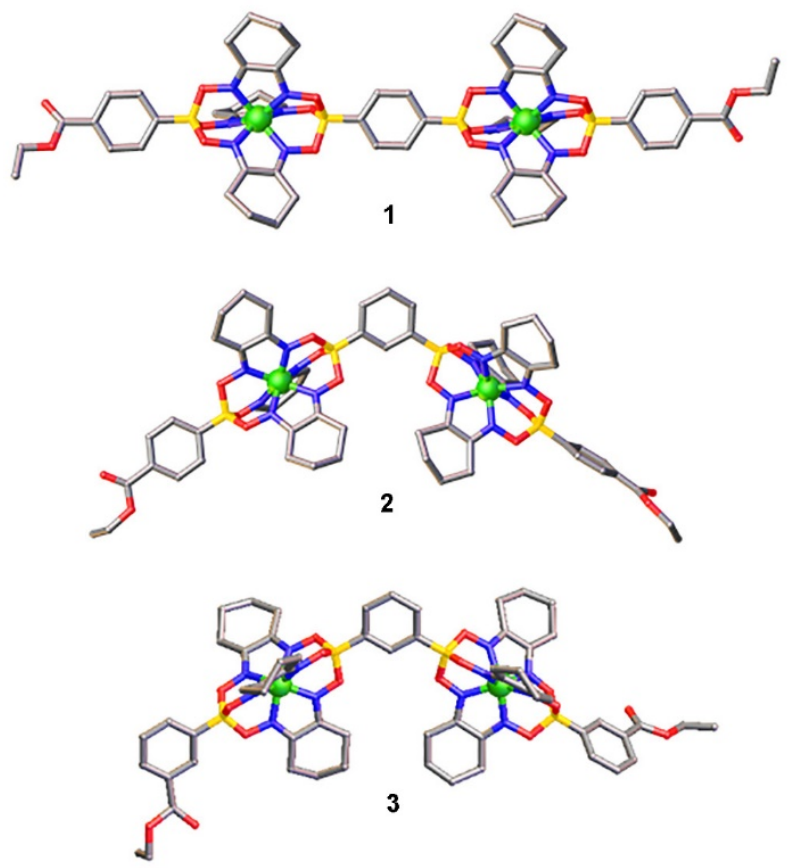

Figure 2. The molecular structures of $\mathbf{1}, \mathbf{2}$ and 3 in the crystal. Hydrogen atoms and solvent molecules $\left(\mathrm{CH}_{2} \mathrm{Cl}_{2}\right)$ are not shown for clarity. Color coding: C: gray, B: yellow, O: red , N: blue, Fe: green.

Saponification of $\mathbf{1 - 3}$ was achieved with $\mathrm{NaOH}$ at $60{ }^{\circ} \mathrm{C}$ using a solvent mixture of $\mathrm{H}_{2} \mathrm{O} / \mathrm{THF} / \mathrm{CH}_{2} \mathrm{Cl}_{2} / \mathrm{MeOH}$ (the 
exact ratio depends on the compound, see the SI). Under these conditions, only minimal decomposition of the iron complexes was observed. The carboxylic acid ligands $4^{\mathbf{- 6}} \mathbf{c a n}$ be dissolved in polar organic solvents such as DMF, DMAc and DMSO, but they are poorly soluble in $\mathrm{MeOH}$ or $\mathrm{CH}_{2} \mathrm{Cl}_{2}$.

In order to demonstrate that the new metalloligands are useful building blocks for the synthesis of more complex nanostructures, we have investigated the formation of an $\mathrm{M}_{4} \mathrm{~L}_{4}$-type MOP. Assemblies of this general formula can be obtained by combination of bent dicarboxylate ligands with $\mathrm{Cu}(\mathrm{II}), \mathrm{Mo}(\mathrm{II}), \mathrm{Cr}(\mathrm{II})$ or $\mathrm{Rh}(\mathrm{II})$ metal precursors. ${ }^{14}$ In the resulting cages, the four ligands are connected by $\mathrm{M}_{2}\left(\mathrm{O}_{2} \mathrm{CR}\right)_{4}$ paddle wheel-like complexes.

The reaction of metalloligand 6 with $\mathrm{Cu}\left(\mathrm{NO}_{3}\right)_{2}\left(\mathrm{H}_{2} \mathrm{O}\right)_{3}$ in $\mathrm{DMF}$ at room temperature resulted in the formation of a crystalline material (7). The very low solubility of the product hampered a solution-based characterization. However, we were able to obtain crystals of sufficient quality for an analysis by single crystal X-ray diffraction (XRD). The results showed that a $\mathrm{Cu}_{4} \mathrm{~L}_{4}$-type cage had indeed formed (Scheme 3 and Figure 3).

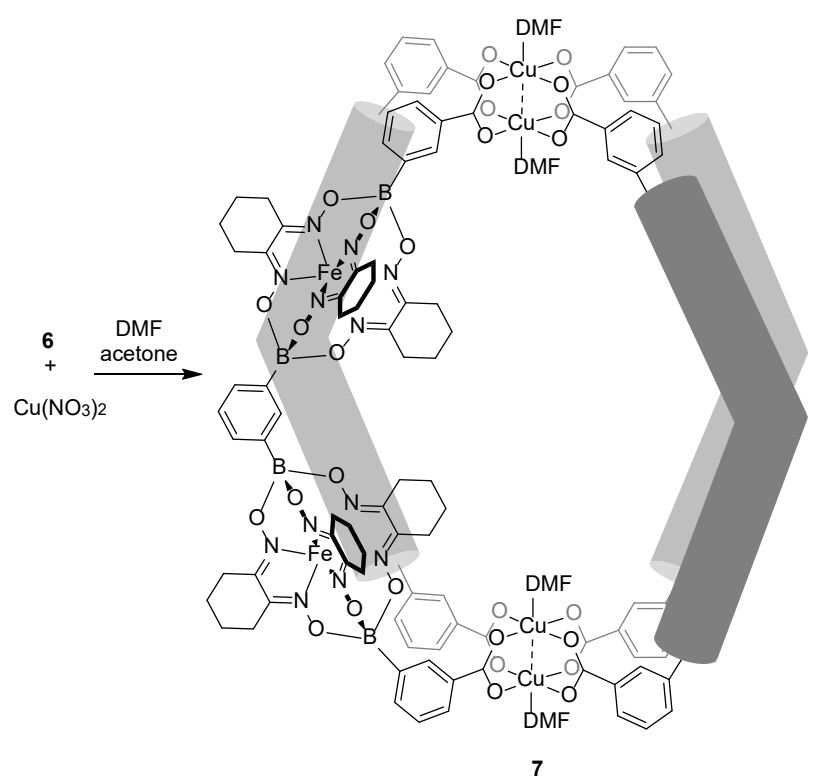

Scheme 3. Synthesis of Coordination Cage 7.

As observed for other $\mathrm{M}_{4} \mathrm{~L}_{4}$ cages, the ligands are connected via $\mathrm{Cu}_{2}\left(\mathrm{O}_{2} \mathrm{C}\right)_{4}$ paddle wheel complexes. Each $\mathrm{Cu}$ is coordinated to one DMF molecule. The $\mathrm{Cu} \cdots \mathrm{Cu}$ distances within the two $\mathrm{Cu}_{2}\left(\mathrm{O}_{2} \mathrm{C}\right)_{4}$ units of 2.618(1) $\AA$ are within the range found for other $\mathrm{Cu}(\mathrm{II})$ carboxylate complexes. ${ }^{16}$ In simple dinuclear $\mathrm{Cu}$ complexes such as $\mathrm{Cu}_{2}(\mathrm{OAc})_{4}\left(\mathrm{OH}_{2}\right),{ }^{17}$ the planes defined by the carboxylate groups cross at an angle of approximately $90^{\circ}$. For cage 7 , one can observe a strong deviation from the ideal square arrangement of the carboxylate ligands. This distortion is evident when the structure of 7 is viewed along the $\mathrm{Cu} \cdots \mathrm{Cu}$ axis (Figure ${ }_{3 \mathrm{c}}$ ). As a consequence of the symmetry reduction at $\mathrm{Cu}$, the eight $\mathrm{Fe}$ centers in $\mathbf{7}$ describe a rectangular- and not a square prismatic structure. One can observe pairs of clathrochelate complexes with closely interdigitated cyclohexyl side chains. The contacts between the aliphatic groups can contribute the stability of the structure via dispersion interactions and solvophobic effects. ${ }^{12 a}$
The overall 'height' of the cage, as defined by the maximum $\mathrm{Cu} \cdots \mathrm{Cu}$ distances, is $2.35 \mathrm{~nm}$. This value is significantly larger than what is found other crystallographically characterized $\mathrm{M}_{4} \mathrm{~L}_{4}$ cages, which show

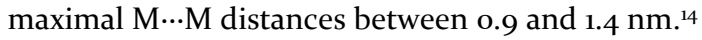

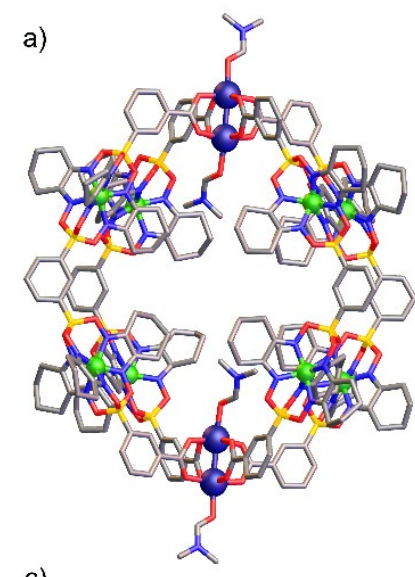

c)

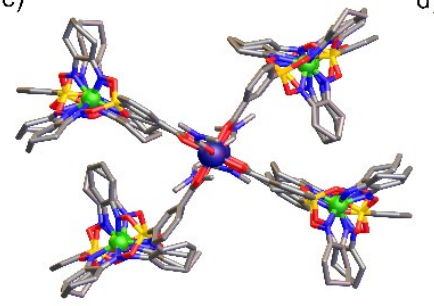

d) b)
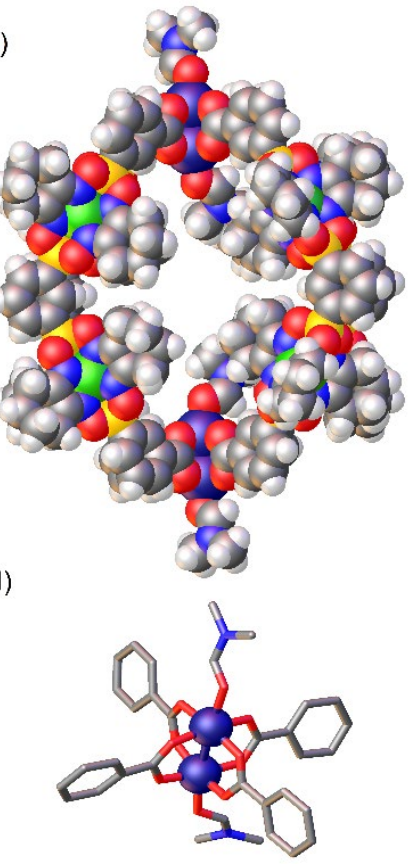

Figure 3. Different views of the molecular structure of $\mathbf{7}$ in the crystal (a-c), and close-up on one of the bridging $\mathrm{Cu}_{2}\left(\mathrm{O}_{2} \mathrm{C}\right)_{4}(\mathrm{DMF})_{2}$ units (d). Hydrogen atoms are not shown for the stick representations a, c, and $d$. Color coding: $C$ : gray, B: yellow, O: red , N: blue, Fe: green.

Charge-neutral MOPs can display permanent porosity in the solid state. ${ }^{4}$ Analysis of the void volume in crystalline $\mathbf{7}$ revealed a solvent accessible volume of $>6000 \AA 3$ represents more than $50 \%$ of the unit cell. Most of the potential void volume is found in-between the cages, and not in the cage interior. In crystalline $\mathbf{7}$, the accessible voids are filled with disordered solvent molecules, which have been removed by the solvent-masking program in Olex2 (for details, see SI). The large voids in crystalline 7 suggested that it might be possible to obtain a material with high porosity. However, the crystals were found to be very fragile, and rapid loss of crystallinity was observed when they were removed from the solvent. Nitrogen sorption experiments were performed after drying the solid for $8 \mathrm{~h}$ at $100^{\circ} \mathrm{C}$ under vacuum. A low porosity with an apparent BET surface area of $176 \mathrm{~m}^{2} / \mathrm{g}$ was deduced from the binding isotherm (see SI). Attempts to increase this value by solvent-exchange procedures were not successful.

\section{Conclusions}

We have developed a protocol, which allows synthesizing nanometer-sized dicarboxylate ligands in two steps from commercial starting materials. The first step of the procedure is an iron-templated condensation reaction between nioxime, a functionalized monoboronic acid, and a diboronic acid. This reaction is inherently unselective, and it gives a mixture of products. The utilization of ester-substituted monoboronic acids allowed separation of the product mixture by size exclusion chromatography. The desired carboxylate ligands 
are then obtained by saponification, and we were able to find conditions, which result in minor decomposition of the iron complexes. In the present work, we describe three different metalloligands, a linear one and two bent ones, but we expect that the procedure is suited for accessing structurally related compounds when different boronic acids are employed. In order to demonstrate that these metalloligands are useful building blocks for metallasupramolecular assemblies, we have prepared a $\mathrm{Cu}_{4} \mathrm{~L}_{4}$-type cage structure. This MOP represents the largest $M_{4} L_{4}$ cage described to date. While we have focused on a molecularly defined cage structure in the present work, we think that ligands such as $\mathbf{4} \mathbf{- 6}$ are also useful compounds for preparing MOFs and related materials.

\section{ASSOCIATED CONTENT}

\section{Supporting Information}

The Supporting Information is available free of charge via the Internet at http://pubs.acs.org.

Experimental details and Figures S1-S22.

\section{AUTHOR INFORMATION}

\section{Corresponding Author}

* To whom correspondence should be addressed.

E-mail: kay.severin@epfl.ch.

\section{Notes}

The authors declare no competing financial interests.

\section{ACKNOWLEDGMENT}

The work was supported by the Swiss National Science foundation and by the Ecole Polytechnique Fédérale de Lausanne (EPFL). We thank Dr Euro Solari and Dr. Pascal Schouwink for help with the crystallographic analyses.

\section{REFERENCES}

1. Steed, J. W.; Atwood, J. L.; Supramolecular Chemistry, $2^{\text {nd }}$ Edition, Wiley Publishing, 2009.

2. For review articles, see: a) Ghasempour, H.; Wang, K.-Y.; Powell, J. A.; ZareKarizi, F.; Lv, X.-L.; Morsali, A., Zhou, H-C. Metal-organic fgrameworks based on multicarboxylate linkers. Coord. Chem. Rev. 2021, 426, 213542. b) Xie, X.-X.; Yang, Y.-C.; Dou, B.-H.; Li, Z.-F.; Li, G. Proton conductive carboxylate-based metal-organic frameworks. Coord. Chem. Rev. 2020, 403, 21310o. c) Ali Akbar Razavi, S.; Morsali, A. Linker functionalized metal-organic frameworks. Coord. Chem. Rev. 2019, 399, 213023. d) Yuan, S.; Feng, L.; Wang, K.; Pang, J.; Bosch, M.; Lollar, C.; Sun, Y.; Qin, J.; Yang, X.; Zhang, P.; Wang, Q.;Zou, L.; Zhang, Y.; Zhang, L.; Fang, Y.; Li, J.; Zhou, H.-C. Stable Metal-Organic Frameworks: Design, Synthesis, and Applications. Adv. Mater. 2018, 30, 1704303. e) Bosch, M.; Yuan, S.; Rutledge, W.; Zhou, H.-C. Stepwise Synthesis of Metal-Organic Frameworks. Acc. Chem. Res. 2017, 50, 857-865.

3. For selected examples, see: a) Ye, Y.; Cook, T. R.; Wang, S.-P.; Wu, J.; Li, S.; Stang, P. J. Self-Assembly of Chiral Metallacycles and Metallacages from a Directionally Adaptable BINOL-Derived Donor. J. Am. Chem. Soc. 2015, 137, 11896-11899. b) Kilbas, B.; Mirtschin, S.; Scopelliti, R.; Severin, K. A solvent-responsive coordination cage. Chem. Sci. 2012, 3, 701-704. c) Mirtschin, S.; Slabon-Turski, A.; Scopelliti, R.; Velders, A. H.; Severin, K. A Coordination Cage with an Adaptable Cavity Size. J. Am. Chem. Soc. 2010, 132, 14004-14005. d) Cotton, F. A.; Murillo, C. A.; Yu, R. Dynamic Equilibrium between Cyclic Oligomers. Thermodynamic and Structural Characterization of a Square and a Triangle. Dalton Trans. 2006, 3900-3905. e) Cotton, F. A.; Murillo, C. A.; Stiriba, S.-E.; Wang, X.; Yu, R. Chiral
Organometallic Triangles with Rh-Rh Bonds. 2. Compounds Prepared from Enantiopure cis- $\mathrm{Rh}_{2}\left(\mathrm{C}_{6} \mathrm{H}_{4} \mathrm{PPh}_{2}\right)_{2}(\mathrm{OAc})_{2}(\mathrm{HOAc})_{2}$ and Their Catalytic Potentials. Inorg. Chem. 2005, 44, 8223-8233. f) Mukherjee, P. S.; Das, N.; Kryschenko, Y. K.; Arif, A. M.; Stang, P. J. Design, Synthesis, and Crystallographic Studies of Neutral Platinum-Based Macrocycles Formed via Self-Assembly. J. Am. Chem. Soc. 2004, 126, 2464-2473. g) Das, N.; Mukherjee, P. S.; Arif, A. M.; Stang, P. J. Facile Self-Assembly of Predesigned Neutral 2D Pt-Macrocycles via a New Class of Rigid Oxygen Donor Linkers. J. Am. Chem. Soc. 2003, 125, 13950-13951. h) Bera, J. K.; Angaridis, P.; Cotton, F. A.; Petrukhina, M. A.; Fanwick, P. E.; Walton, R. A. Incorporating Multiply Bonded Dirhenium Species $\left[\operatorname{Re}_{2}\right]^{n+}(n=4$ or 5$)$ into Assemblies Containing Two or More Such Units. J. Am. Chem. Soc. 20o1, 123 , 1515-1516.

4. For review articles, see: a) Gosselin, E. J.; Rowland, C. A.; Bloch, E. D. Permanently Microporous Metal-Organic Polyhedra. Chem. Rev. 2020. https://doi.org/10.1021/acs.chemrev.9boo803. b) El-Sayed, E.-S. M.; Yuan, D. Metal-Organic Cages (MOCs): From Discrete to Cagebased Extended Architectures. Chem. Lett. 2020, 49, 28-53. c) Decker, G. E.; Lorzing, G. R.; Deegan, M. M.; Bloch, E. D. MOF-mimetic molecules: carboxylate-based supramoleculkar complexes as molecular metal-organic framework analogues. J. Mater. Chem. A 2020, 8, 4217-4229. d) Mollick, S.; Fajal, S.; Mukherjee, S.; Ghosh, S. K. Stabilizing Metal-Organic Polyhedra (MOP): Issues and Strategies. Chem. Asian J. 2019, 14, 3096-3108. e) Hosono, N.; Kitagawa, S. Modular Design of Porous Soft Materials via Self-Organization of Metal-Organic Cages. Acc. Chem. Res. 2018, 51, 2437-2446. f) Ahmad, N.; Chughtai, A. H.; Younus, H. A.; Verpoort, F. Discrete metalcarboxylate self-assembled cages: design, synthesis and applications. Coord. Chem. Rev. 2014, 280, 1-27. g) Köberl, M.; Cokoja, M.; Herrmann, W. A.; Kühn, F. E. From molecules to materials: molecular paddle-wheel synthons of macromolecules, cage compounds and metal-organic frameworks. Dalton Trans. 2011, 40, 6834-6859.

5. a) Voloshin, Y. Z.; Belaya, I. G.; Kramer, R. K. Cage Metal Complexes; Clathrochelates Revisited; Springer International Publishing: New York, 2017. b) Voloshin, Y. Z.; Kostromina, N. A.; Kramer, R. K. Clathrochelates: Synthesis, Structure and Properties; Elsevier Science: Amsterdam, The Netherlands, 2002.

6. For review articles on metalloligands, see: a) Hardy, M.; Lützen, A. Better Together: Functional Heterometallic Macrocyclic and Cagelike Assemblies. Chem. Eur. J. 2020, DOI: 10.1002/chem.202001602. b) Li, F.; Lindoy, L. F. Metalloligand strategies for assembling heteronuclear nanocages - recent developments. Aust. J. Chem. 2019, 72, 731-741. c) Gil-Rubio, J.; Vicente, J. The Coordination and Supramolecular Chemistry of Gold Metalloligands. Chem. Eur. J. 2018, 24, 32-46. d) Srivastava, S.; Gupta, R. Metalloligands to material: design strategies and network topologies. CrystEngComm 2016, 18, 9185-9208. e) Li, L.; Fanna, D. J.; Shepherd, N. D.; Lindoy, L. F.; Li, F. Construccting coordination nanocages: the metalloligand approach.J. Incl. Phenom. Macrocycl. Chem. 2015, 82, 3-12. f) Kumar, G.; Gupta, R. Molecularly designed architectures - the metalloligand way. Chem. Soc. Rev. 2013, 42, 9403-9453. g) Constable, E. C. Expanded ligandsan assembly principle for supramolecular chemistry. Coord. Chem. Rev. 2008, 252, 842-855.

7. a) Jansze, S. M.; Severin, K. Clathrochelate Metalloligands in Supramolecular Chemistry and Materials Science. Acc. Chem. Res. 2018, 51, 2139-2147. b) Wise, M. D.; Severin, K. Functionalised Clathrochelate Complexes - New Building Blocks for Supramolecular Structures. Chimia 2015, 69, 191-196.

8. Marmier, M.; Wise, M. D.; Holstein, J. J.; Pattison, P.; Schenk, K.; Solari, E.; Scopelliti, R.; Severin, K. Carboxylic Acid Functionalized Clathrochelate Complexes: Large, Robust, and Easy-to-Access Metalloligands. Inorg. Chem. 2016, 55, 4006-4015.

9. Lebed, E. G.; Belov, A. S.; Dolganov, A. V.; Vologzhanina, A. V.; Szebesczyk, A.; Gumienna-Kontecka, E.; Kozlowski, H.; Bubnov, Y. N.; Dubey, I. Y.; Voloshin, Y. Z. First clathrochelate iron and cobalt(II) tris-dioximates with reactive apical substituents Inorg. Chem. Commun. 2013, 30, 53-57.

10. Giraldi, E.; Depallens, A.B.; Ortiz, D.; Fadaei-Tirani, F.; Scopelliti, R.; Severin, K. Boronate Ester-Capped Helicates. Chem. Eur. J. 2020, doi:10.1002/chem.202001392.

11. Planes, O. M.; Schouwink, P. A.; Bila, J. L.; Fadaei-Tirani, F.; Scopelliti, R.; Severin, K. Incorporation of Clathrochelate-Based 
Metalloligands in Metal-Organic Frameworks by Solvent-Assisted Ligand Exchange. Cryst. Growth Des. 2020, 20, 1394-1399.

12. a) Jansze, S. M.; Wise, M. D.; Vologzhanina, A. V.; Scopelliti, R.; Severin, K. $\mathrm{Pd}^{\mathrm{II}_{2}} \mathrm{~L}_{4}$-type coordination cages up to three nanometers in size. Chem. Sci. 2017, 8, 1901-1908. b) Ardavan, A.; Bowen, A. M.; Fernandez, A.; Fielding, A. J.; Kaminski, D.; Moro, F.; Muryn, C. A.; Wise, M. D.; Ruggi, A.; McInnes, E. J. L.; Severin, K.; Timco, G. A.; Timmel, C. R.; Tuna, F.; Whitehead, G. F. S.; Winpenny, R. E. P. Engineering coherent interactions in molecular nanomagnet dimers. npj Quantum Inf 2015, 1, 15012. c) Wise, M. D.; Ruggi, A.; Pascu, M.; Scopelliti, R.; Severin, K. Clathrochelate-based bipyridylligands of nanoscale dimensions: easy-to-access building blocks for supramolecular chemistry. Chem. Sci. 2o13, 4, 1658-1662.

13. Using triboronic acids instead of diboronic acids, it is also possible to make tritopic pyridyl ligands. See: Jansze, S. M.; Ortiz, O.; Fadaei Tirani, F.; Scopelliti, R.; Menin, L.; Severin, K. Inflating facecapped $\mathrm{Pd}_{6} \mathrm{~L}_{8}$ coordination cages. Chem. Commun. 2018, 54, 95299532.

14. a) Boer, S.A.; Cao, W.; Glascott, B.K.; Turner, D.R. Towards a Generalized Synthetic Strategy for Variable Sized Enantiopure $\mathrm{M}_{4} \mathrm{~L}_{4}$ Helicates. Chemistry 2020, 2, 613-625. b) Taggart, G. A.; Lorzing, G. R.; Dworzak, M. R.; Yap, G. P. A.; Bloch, E. D. Synthesis and characterization of low-nuclearity lantern-type porous coordination cages. Chem. Commun. 2020, 56, 8924-8927. c) Bloch, W. M.; Babarao R.; Schneider, M. L. On/off porosity switching and post-assembly modifications of $\mathrm{Cu}_{4} \mathrm{~L}_{4}$ metal-organic polyhedra. Chem. Sci., 2020, 11, 3664-3671. d) Craig, G. A.; Larpent, P.; Urabe, H.; Legrand, A.; Bonneau, M.; Kusaka, S.; Furukawa, S. Hysteresis in the gas sorption isotherms of metal-organic cages accompanied by subtle changes in molecular packing. Chem. Commun. 2o2o, 56, 3689-3692. e) Craig, G. A.; Larpent, P.; Kusaka, S.; Matsuda, R.; Kitagawa S.; Furukawa, S. Switchable gate-opening effect in metal-organic polyhedra assemblies through solution processing. Chem. Sci., 2018, 9, 64636469. f) Kang, J.; Chen, L.; Cui, H.; Zhang, L.; Su, C.-Y. N-H Insertion Reactions Catalyzed by a Dirhodium Metal - Organic Cage: A Facile and Recyclable Approach for $\mathrm{C}-\mathrm{N}$ Bond Formation. Chin. J. Chem. 2017, 35, 964-968. g) Chen, L.; Kang, J.; Cui, H.; Wang, Y.; Liu, L.; Zhang, L.; Su, C.-Y. Homochiral coordination cages assembled from dinuclear paddlewheel nodes and enantiopure ditopic ligands: syntheses, structures and catalysis. Dalton Trans., 2015, 44, 1218012188. h) Chen, L.; Yang, T.; Cui, H.; Cai, T.; Zhang, L.; Su, C.-Y. A porous metal-organic cage constructed from dirhodium paddlewheels: synthesis, structure and catalysis. J. Mater. Chem. A, 2015, 3 , 20201-20209. i) Boer, S. A.; Turner, D. R.; Self-selecting homochiral quadruple-stranded helicates and control of supramolecular chirality. Chem. Commun., 2015, 51, 17375-17378. j) Brega, V.; Zeller, M.; He, Y.; Peter Lu, H.; Klosterman, J. K. Multi-responsive metal-organic lantern cages in solution. Chem. Commun. 2015, 51, 5077-508o, k) Li, J.-R.; Yu, J.; Lu, W.; Sun, L.-B.; Sculley, J.; Balbuena, P. B.; Zhou, H.-C. Porous materials with pre-designed single-molecule traps for $\mathrm{CO}_{2}$ selective adsorption. Nat. Commun. 2013, 4, 1538-1546, l) Lu, W.; Yuan, D.; Yakovenko, A.; Zhou, H.-C. Surface functionalization of metalorganic polyhedron for homogeneous cyclopropanation catalysis. Chem. Commun. 2011, 47, 4968-4970, m) Li, J.-R.; Zhou, H.-C. Bridging-ligand-substitution strategy for the preparation of metalorganic polyhedra. Nat. Chem. 2010, 2, 893-898, n) Jaya Prakash, M.; Oh, M.; Liu, X.; Han, K. N.; Seong, G. H.; Lah, M. S. Edge-directed [(M2)2 4 4] tetragonal metal-organic polyhedra decorated using a square paddle-wheel secondary building unit. Chem. Commun. 2o10, 46, 2049-2051. o) Li, J.-R.; Yakovenko, A. A.; Lu, W.; Timmons, D. J.; Zhuang, W.; Yuan, D.; Zhou, H.-C. Ligand Bridging-Angle-Driven Assembly of Molecular Architectures Based on Quadruply Bonded Mo-Mo Dimers. J. Am. Chem. Soc. 2010, 132, 17599-17610.

15. Poor solubility is often observed for $\mathrm{M}_{4} \mathrm{~L}_{4}$-type MOPs (see ref.

14)

16. Doedens, R. J. Structure and Metal-Metal Interactions in Copper(II) Carboxylate Complexes. Progr. Inorg. Chem. 1976, 21, 209-230.

17. Brown, G. M.; Chidambaram, R. Dinuclear Copper(II) Acetate Monohydrate: a Redetermination of the Structure by Neutron Diffraction Analysis. Acta Cryst. 1973, B29, 2393 - 2403. 


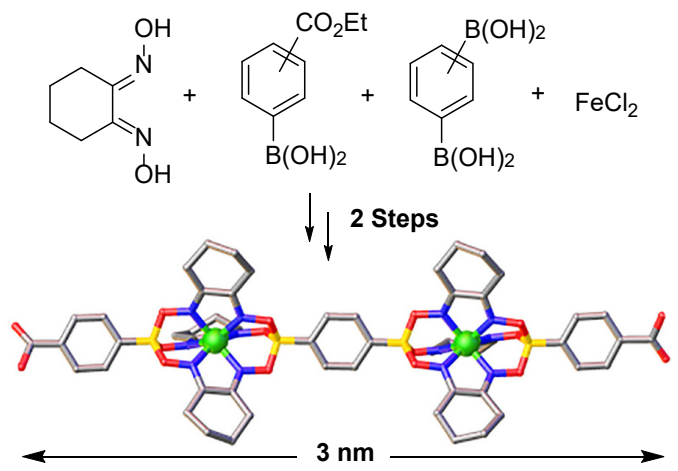

Synopsis: A simple two-step protocol allows preparing linear and bent dicarboxylate ligands with lengths of up to three nanometers from commercially available compounds. In order to demonstrate that these metalloligands are useful building blocks for metallasupramolecular assemblies, a $\mathrm{Cu}_{4} \mathrm{~L}_{4}$-type cage structure was prepared. 